\title{
Epidemiology of Preventable Drug-Related Problems (DRPs) Among Hospitalized Children at KAMC-Jeddah: a Single-Institution Observation Study
}

This article was published in the following Dove Press journal:

Drug, Healthcare and Patient Safety

\author{
Aeshah AlAzmi $\mathbb{D}^{1,2}$ \\ Omaima Ahmed ${ }^{2}$ \\ Hani Alhamdan' \\ Hanan AIGarni ${ }^{3}$ \\ Rawan Mohammed Elzain ${ }^{3}$ \\ Rihad S AIThubaiti ${ }^{3}$ \\ Mohammed Aseeri ${ }^{1}$ \\ Adnan Al Shaikh ${ }^{4}$ \\ 'Ministry of National Guard Health \\ Affairs (MNGHA), King Abdulaziz \\ Medical City (KAMC), Pharmaceutical \\ Care Services Department, Clinical \\ Pharmacy Section, Jeddah, Saudi Arabia; \\ ${ }^{2}$ Princes Noorah Oncology Center \\ (PNOC), Pediatric Oncology/ \\ Hematology/BMT Section, King Abdulaziz \\ Medical City (KAMC), Jeddah, Saudi \\ Arabia; ${ }^{3}$ Ibn Sina National College for \\ Medical Studies, Pharmacy College, \\ Jeddah, Saudi Arabia; ${ }^{4}$ Ministry of \\ National Guard Health Affairs \\ (MNGHA), King Abdulaziz Medical City \\ (KAMC), King Saud bin Abdulaziz \\ University for Health Sciences, \\ Department of Pediatrics, Chemistry \\ Laboratory, Community Medicine, \\ Jeddah, Saudi Arabia
}

Correspondence: Aeshah AIAzmi KAMC 6255, Jeddah, 2I 423, Saudi Arabia Tel +966 I22266666 Ext 2286I

Email Aeshah.alazmi@gmail.com

\begin{abstract}
Aim: Drug-related problems (DRPs) "are the unwanted effects of drugs that potentially lead to a harmful outcome" thereby requiring considerable attention. Hospitalized pediatric patients, in particular, represent a population at risk of DRPs. The epidemiology of preventable DRPs among children in Saudi Arabia remains scarce, which thus poses distinct challenges to all healthcare professionals. We aim to characterize preventable DRPs among hospitalized children at KAMC-Jeddah.
\end{abstract}

Methods: A prospective observational study of children ( $\leq 15$ years) admitted to pediatric units (excluding cancer units) at KAMC-Jeddah over a 3-month period (May 29 to August 30, 2016) is carried out to determine the incidence of preventable DRPs and investigate the possible associated factors (gender, age, admission location, type of admission, and number of medications).

Results: A total of 319 DRPs were identified among 235 patients, of which 280 DRPs $(87.8 \%, 280 / 319)$ were deemed preventable. The majority of preventable DRPs were related to dose selection $(78 \%, 219 / 280)$. None of the preventable DRPs were life threatening or fatal, and the majority were assessed as moderate in severity $(94.3 \%, 264 / 280)$. There was no significant difference between DRP incidences with age mean $3.5(\mathrm{P}=0.389)$, gender mean $(\mathrm{P}=0.436)$, and weight mean $13.47(\mathrm{P}=0.323)$. Younger children (age $\leq 2 \mathrm{years})$ admitted to PICU were more likely to have DRP (OR 4.44, 95\% CI, 1.87 to $10.52, \mathrm{P}=0.00001$ ). Scheduled admissions were 2.89 times more likely to be exposed to DRP compared to transferred admissions (OR 2.8, 95\% CI, 1.83 to $4.70, \mathrm{P}=0.005$ ). Additionally, DRP incidences increased proportionally to the number of medications.

Conclusion: Our data suggest that establishing appropriate prevention strategies towards improvement and safety in medicine use among this vulnerable patient population is a high priority. Keywords: children, risk factors, drug-related problems, hospitalized pediatric patients

\section{Introduction}

There are various definitions in the literature used by different organizations for dverse drug events (ADEs), adverse drug reactions (ADRs), and medication errors (MEs). ADE is defined as "an injury resulting from the use of a drug". ${ }^{1}$ ADE can occur irrespective of whether or not the drug is suspected to be the cause. ADR is defined as harm that results from a normal medication dose. ${ }^{2}$ The main difference between these terms is that ADR is a harm usually suspected to be related to the drug and may occur despite the appropriate prescribing and dosing, whereas ADE is harm associated with any dose of a drug, whether or not the dose is "normally used 
in man" or due to other confounders that arise during treatment but are not necessarily caused by the pharmacology of the drug itself. ${ }^{3}$

$\mathrm{ME}$ "is any error in the process of prescribing, dispensing, or administering a drug, whether there are any adverse consequences or not", 4 whereas the National Coordinating Council for Medication Error Reporting and Prevention (NCC MERP) defines ME “any preventable event that may cause or lead to inappropriate medication use or patient harm while the medication is in the control of the health care professional, patient, or consumer". 5 To eliminate the confusion regarding these terms, the NCCMER stated that "all ADEs are associated with patient harm, but not all ADEs are caused by an error"; therefore, ADR is a subtype of an ADE. ${ }^{5}$ Drugrelated problem (DRP) is defined as "an event or circumstance that involves a patient's drug therapy that actually or potentially interferes with a desired patient outcome"., Based on the definition of MEs and DRPs, DRPs are likely to be the most related to MEs. Studies on DRPs among pediatric population are limited. The results of a Harvard medical practice study showed that nearly $4 \%$ of the prolonged hospitalized patients were due to medical injuries, and almost $70 \%$ of the detected medical injuries were a result of preventable errors. ${ }^{2,3}$ Drug use complications were found to be the most commonly detected medical injuries which accounted for $19.4 \% .{ }^{4}$ Nearly $80 \%$ of the detected ADEs originated during the drug ordering stage wherein $34 \%$ were related to incorrect dosing. ${ }^{6}$ A couple of studies have found that pediatric hospital admission and emergency room visits secondary to DRPs are more common among children than adults. ${ }^{7-9}$ Many studies have highlighted the different rates and causes of DRPs. ${ }^{10-15}$

Prescribing a drug for children is considered a challenging process for all healthcare providers and poses an economic burden to the healthcare system. ${ }^{16-23}$ Implementing the computerized physician order entry (CPOE) is found to have an enormous impact in optimizing medication use and reducing medication errors. ${ }^{24-28}$ In view of mitigating DRPs among hospitalized patients, the CPOE system recently introduced at KAMC-J has resulted in a significant reduction in the incidence of DRPs among hospitalized children, while the results also showed that the majority of reported DRPs were found to be preventable. ${ }^{29-31}$ A recent systemic review that looked at the incidence and preventability of DRPs associated with hospital readmission showed variable results. The readmissions were found to be preventable in $5-87 \%$ of the cases (median 69\%, IQR 19-84\%) with a median readmission rate due to drug use of $21 \%$ (IQR 14-23\%). Due to the limited number of included studies that focused on preventability, the authors stated that an "accurate estimate of the proportion of preventable drug-related readmissions is impossible". ${ }^{32}$ While there are a limited number of published studies that address DRPs in Saudi Arabia, with the main focus on the prevalence and impact of DRP among hospitalized patients. ${ }^{29-31,40,41}$ No study has been conducted to examine preventable DRPs among the children population. The present study is the first of its kind to be conducted among hospitalized children in Saudi Arabia. The main aim is to address the epidemiology and characteristics of the preventable DRPs among hospitalized pediatric patients at KAMC-Jeddah and to ascertain if there is any association between DRP and the location, gender, type of admission, and number of medications. In addition, we hope to provide insights into the DRPs encountered among hospitalized pediatric patients that can help in finding the appropriate solutions.

\section{Materials and Methods Study Design}

A prospective observational study was conducted at King Abdulaziz Medical City (KAMC)-Jeddah, Kingdom of Saudi Arabia (KSA). To study MEs with a view to addressing preventable ADRPs in children, we used the same chart review method for data collection proposed by Ghaleb et $\mathrm{al}^{42}$ and Dean et al. ${ }^{43}$ Patients included were children aged $\leq 15$ years who were admitted to the emergency department (ED), pediatric surgical ward, pediatric medical ward, pediatric intensive care unit (PICU), and neonatal intensive care unit (NICU) but excluding patients admitted to the pediatric cancer units. Data were collected over a 3-month period (May 29 to August 30, 2016). Children were grouped into five age-groups, modified from the International Conference of Harmonization Guideline E11 as follows: $\leq 1$ month; $>1$ month to $\leq 2$ years; $>2$ to $\leq 6$ years; $>6$ to $\leq 12$ years; and $>12$ to $\leq 15$ years. $^{39}$

\section{Data Collection}

The electronic medical records of all children were identified and assessed by three trained pharmacists during weekdays (08:00 a.m. to 17:00 pm) from Sunday to Thursday to identify DRPs according to the most recognized and suitable criteria system given by the Pharmaceutical Care Network Europe (PCNE). ${ }^{6}$ For standardization, they recorded the patients' demographics (age, gender, and diagnosis using WHO ICD version $10^{46}$ ), location, drug chart with number of medications, drug type using the Anatomic Therapeutic 
Chemical (ATC) classification (WHO-ATC). In this "ATC classification system, the active substances are classified in a hierarchy with five different levels. The system has fourteen main anatomical/pharmacological groups or 1 st levels, ${ }^{47}$ type of admission (transferred, ED, Scheduled), and laboratory data associated with any potential and/or identified DRPs. A DRP was defined as "an event or circumstance involving drug therapy that actually or potentially interferes with the desired health outcome". DRPs can be preventable or non-preventable. Based on the definition of MEs and DRPs, we may define preventable DRPs in this study as MEs that we use as the primary outcome measure.

Once a potential DRP was identified, the pharmacist recorded the type of DRP and causes which are then peer reviewed by an expert panel consisting of two pediatric physicians (one staff physician and one consultant), two pharmacists (one staff pharmacist and one pediatric clinical pharmacist), and a researcher. For the purpose of this study, if the identified DRPs are the result of "errors in the medication use process (e.g. prescribing, dispensing, administering or monitoring)", it was considered as a medication error (Preventable ADRP). Consensus discussion and agreement within the group was sought in order to reach a final decision about validation of DRPs. Subsequently, each DRP case was independently reviewed and assessed by two members for preventability using the criteria provided by Schumock and Thornton (1992). ${ }^{44}$ Each preventable DRP was scored for its severity in terms of potential patient outcome on a scale of 0 to 10 (where 0 represents no potential adverse effect and 10 a DRP that would result in death) using the validated scale of medication errors published by Dean and Barber (1999). ${ }^{45}$ The mean score for each DRP was used as an index of severity, a mean score less than 3 was considered to be a minor outcome (very unlikely to have an adverse effect), mean score between 3 and 7 was considered to be moderate (likely to cause some adverse effects or interfere with therapeutic goals, but very unlikely to result in death or lasting impairment), and a mean score greater than 7 was considered to be a severe outcome (likely to cause death or lasting impairment).

\section{Classification of DRPs}

The PCNE system is well structured and has domains with distinct codes for problems, causes, and potential interventions. On that basis, we adopt the definition and classification of DRPs using the PCNE classification system (Version 7.0). ${ }^{6}$ DRP in the problem domains is defined as "the expected or unexpected event or circumstance that is, or might be wrong, in therapy with drugs". And while each problem has a cause, DRP in the cause domain is defined as "the action (or lack of action) that leads up to the occurrence of a potential or real problem". The aim is to determine the incidence of preventable DRPs and investigate the possible associated factors (gender, age, admission location, type of admission, and number of medications).

\section{Statistical Analysis}

A descriptive analysis was performed to summarize and describe the details of the study population such as age, gender, diagnosis, and medication class using WHO-ATC. Data are presented as number, percentage, median, and interquartile range (IQR). We reported the rates of DRPs by dividing the number of patients experiencing preventable DRP by the total number of study participants. Bivariate analysis with chi-square and $t$-statistic test was used to determine the association between DRPs' occurrence with location, type of admission, gender, age, weight, and number of medications. Independent Samples $t$-Test and binary logistic regression were used to determine the association between DRPs and location, type of admission (transferred, ED, Scheduled), and number of medications. The results were reported as odds ratio (OR). Any $\mathrm{P}$ value of less than 0.05 was considered to be statistically significant. All data were analyzed using the SPSS software.

\section{Ethical Approval}

Informed consent obtained from the parent or legal guardian of all patients provided written informed consent to participate in this research, in accordance with the Declaration of Helsinki. This study was approved in 2018 by the King Abdullah International Medical Research Center's (KAIMRC) protocol number RJ18/056/J.

\section{Results}

\section{Population Characteristics}

A total of 655 pediatric patients were seen during the study period (May 29 to August 30, 2016). Of those 655 patients, 235 patients $(35.9 \%, 235 / 655)(E D=49$, Surgical $=62$, Medical $=76, \mathrm{PICU}=22$, and $\mathrm{NICU}=26$ ) had at least one DRP and were thus included in the study. Male $(n=137)$ to female $(n=98)$ ratio was 1.4 to 1 with a median age of 1.5 years, IQR (6 months to 6 years). A total of 1240 drugs were recorded during the study periods as follows: total of 186 drugs were given to 65 patients in which less than 5 drugs were identified per prescription, 896 drugs were given to 150 
patients who received 5 to 10 drugs per their prescription, and 157 drugs were recorded for 20 patients who received more than 10 drugs per prescription. The largest age group included was more than a month to less than 2 years of age. Table 1 provides details of patients' characteristics.

\section{Total Diseases Associated with Identified DRPs}

The number of patients included with DRPs was 235. Using the WHO-ICD 10 classifications for disease diagnoses, a total of 23 different diagnoses were identified in 235 patients, with the most reported disease being respiratory system diseases (pneumonia and bronchiolitis) followed by infectious disease (sepsis, upper respiratory tract infection, urinary tract infection, wound infection). Figure 1 provides the recorded disease frequency in 235 patients with DRPs.

\section{Incidence of Preventable DRPs}

A total of 319 DRPs were identified in 235 patients, of which 280 DRPs $(87.7 \%, 280 / 319)$ deemed preventable. The incidence of preventable DRPs from the identified total DRPs per study area was 92 preventable DRPs in medical ward $(28.8 \%, 92 / 319)$, followed by 77 in surgical ward $(24.1 \%, 77 / 319), 48$ in $\operatorname{ED}(15 \%, 48 / 319), 33$ in NICU (10.3\%, 33/319), and 30 in PICU (9.4\%, 30/319) in which one child can contribute to more than one preventable DRP. Table 2 provides details of the frequency of preventable DRPs in every study area.

\section{Drug Classes Involved with the Occurrence of Preventable DRPs}

Using the WHO-ATC classification system for medication, nine groups of ATC anatomical group (1st level) were reported. The most often involved in the preventable DRPs were "anti-infective for systemic use" (J) $(32.9 \%, n=92 / 280)$, followed by "Blood and blood forming organs" (B) $(25 \%, \quad n=70 / 280), \quad$ and "Alimentary tract and metabolism"(A) $(25 \%, n=70 /$ 280). Table 3 provides details of the most frequently identified ATC anatomical group with preventable DRPs.

\section{Epidemiology of DRPs DRPs Category}

Overall, three main causes were reported in the identified 280 preventable DRPs. The vast majority were related to dose selection $(74.6 \%, 209 / 280)$. The second most frequent cause was related to drug choice $(22.9 \%$, $64 / 280)$, and then drug use $(2.5 \%, 7 / 280)$. Table 4 summarizes the category and most frequently reported causes of preventable DRPs according to PCNE classification.

Table I Patients' Characteristics (Total Number of Patients Experienced DRPs, N=235)

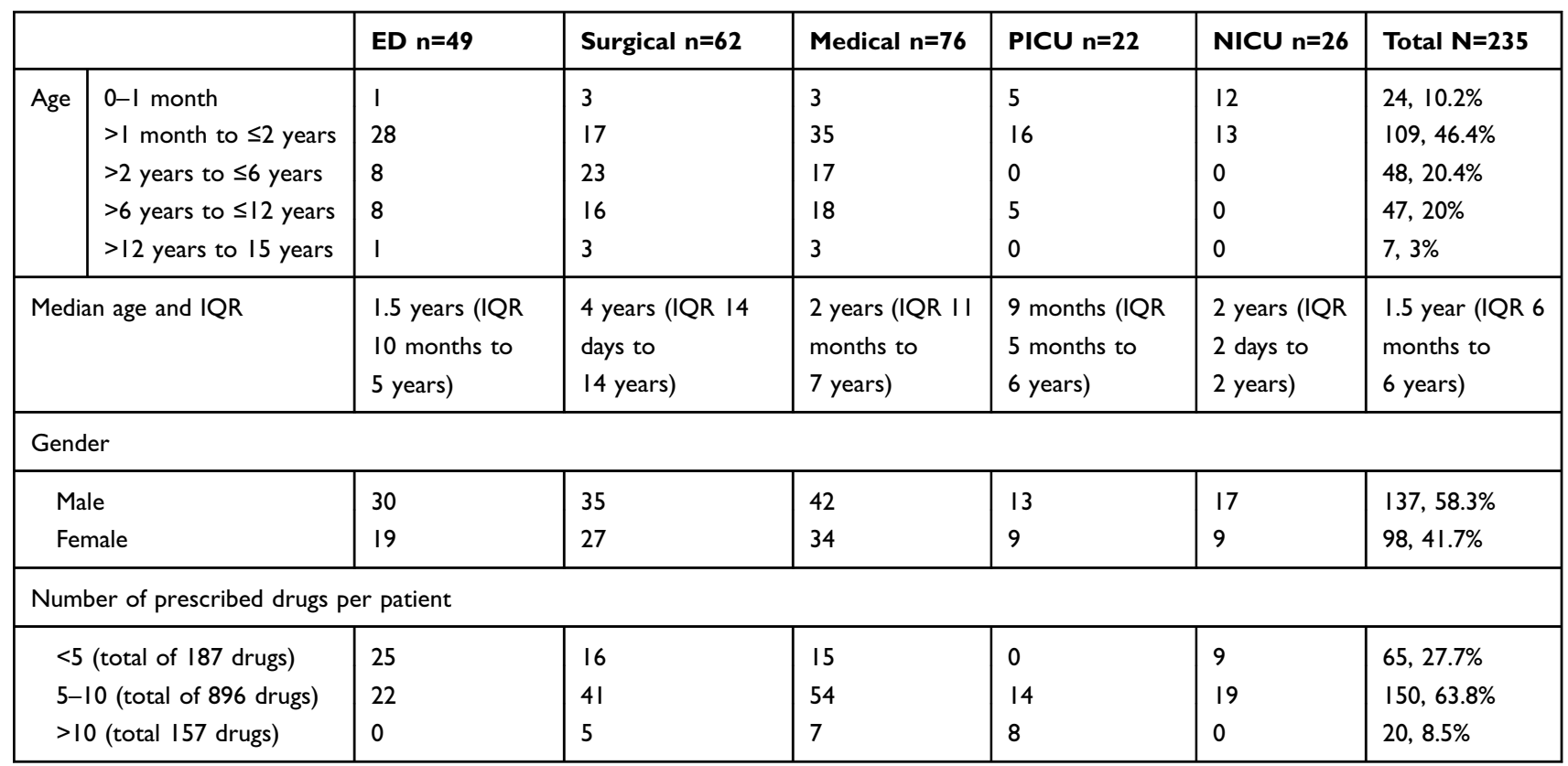

Abbreviations: ED, emergency department; PICU, pediatric intensive care unit; NICU, neonatal intensive care unit; IQR, interquartile range; $n$, number of included patients with DRPs per study area; $N$, total number of patients with DRPs. 


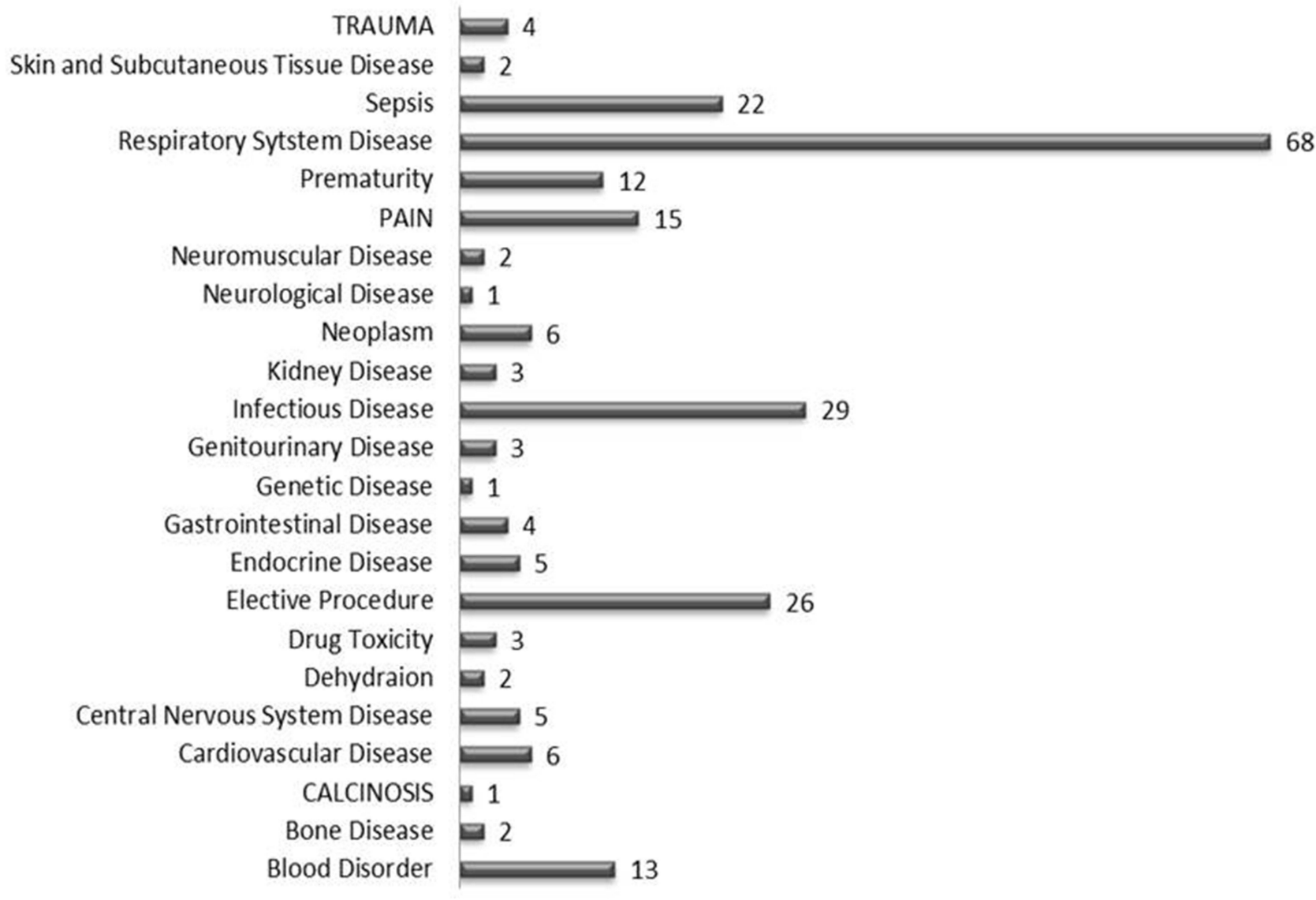

Figure I A total of 23 disease systems were recorded in 235 patients with DRPs.

\section{DRPs' Severity}

None of the identified preventable DRPs was life-threatening or fatal. The majority of preventable DRPs were assessed as moderate in severity $(94.3 \%, 264 / 280)$, minor $(5.4 \%, 15 /$ $280)$, and severe $(0.36 \%, 1 / 280)$.

\section{Risk Factors Associated with DRPs}

Admission Location

We found a significant association between the incidence of preventable DRPs and the type of admission. Children in PICU are more likely to have DRP

Table 2 Frequency of Detected Preventable DRPs (280) Identified in 235 Patients Based on Age and Gender per Study Area Provided in Percentage $(\%, \mathrm{~N} / \mathrm{N})$

\begin{tabular}{|l|l|l|l|l|l|l|l|}
\hline $\begin{array}{l}\text { Frequency of Preventable } \\
\text { DRPs per Age and Gender }\end{array}$ & ED $\mathbf{n = 4 8}$ & Surgical $\mathbf{n = 7 7}$ & Medical N=92 & PICU $\mathbf{n = 3 0}$ & NICU $\mathbf{n = 3 3}$ & Total N=280 (\%, $\left.\mathbf{n}^{\mathbf{b}} / \mathbf{N}^{\mathbf{a}}\right)$ \\
\hline Age & $0-$ I month & $\mathrm{I}$ & 4 & 4 & 2 & 14 & $25,8.9 \%$ \\
& $>$ Imonth to $\leq 2$ years & $3 \mathrm{I}$ & 19 & 44 & 21 & 19 & $134,47.9 \%$ \\
& $>2$ years to $\leq 6 y e a r s$ & 7 & 30 & 19 & 0 & 0 & $56,20 \%$ \\
& $>6 y e a r s$ to $\leq 12$ years & 6 & 22 & 20 & 7 & 0 & $55,19.6 \%$ \\
& $>12$ years to I5 years & 3 & 2 & 5 & 0 & 0 & $10,3.6 \%$ \\
\hline \multirow{2}{*}{ Gender } & Frequency in Male & 26 & 47 & 49 & 18 & 25 & $165,58.9 \%$ \\
& Frequency in Female & 22 & 30 & 43 & 12 & 8 & $115,41 \%$ \\
\hline
\end{tabular}

Notes: ${ }^{\mathrm{a}} \%$ calculated of total number of preventable DRPs identified in each ward; ${ }^{\mathrm{b}}$ Frequency of identified preventable DRPs, as one child can contribute to more than one preventable DRP.

Abbreviations: DRPs, preventable drug-related problems; ED, emergency department; PICU, pediatric intensive care unit; NICU, neonatal intensive care unit; $\mathrm{n}$, number of included patients with preventable DRPs per study area; N, total number of patients with preventable DRPs. 
Table 3 Anatomical Therapeutic Chemical (ATC) Ist Level Classification for the Reported Preventable DRPs

\begin{tabular}{|l|l|}
\hline ATC & Frequency $\left(\%, \mathbf{n}^{\mathbf{b}} / \mathbf{N}^{\mathbf{a}}\right)$ \\
\hline A & $25 \%, 70 / 280$ \\
B & $25 \%, 70 / 280$ \\
C & $1 \%, 3 / 280$ \\
H & $1.8 \%, 5 / 280$ \\
J & $32.9 \%, 92 / 280$ \\
L & $0.7 \%, 2 / 280$ \\
M & $3.9 \%, 11 / 280$ \\
N & $6.8 \%, 19 / 280$ \\
R & $2.9 \%, 8 / 280$ \\
\hline
\end{tabular}

Notes: $\%$ calculated of total number of preventable DRPs identified in each ward; bFrequency of identified drug class in the preventable DRPs, as one child can contribute to more than one preventable DRP; ATC anatomical groups ( 9 identified groups involved in the preventable DRPs).

Abbreviations: ATC, anatomical therapeutic chemical; DRPs, preventable drugrelated problems; A, alimentary tract and metabolism; B, blood and blood forming organs; C, cardiovascular system; $\mathrm{H}$, systemic hormonal preparations, excluding sex hormones and insulin; J, anti-infective for systemic use; L, antineoplastic and immune-modulating agents; $M$, musculoskeletal system; $N$, nervous system; $R$, respiratory system; $\mathrm{n}$, number of identified cases.

compared to other wards (OR 4.44, 95\% CI, 1.87 to $10.52, \mathrm{P}=0.00001)$.

\section{Type of Admission}

Patients admitted for either scheduled or post-emergency visit were more likely to be exposed to DRPs compared to transferred admission and odds ratio (OR 2.8, 95\% CI, 1.83 to $4.70, \mathrm{P}=0.005$ and $\mathrm{OR} 1.8,95 \% \mathrm{CI}, 1.45$ to 4.42 , $\mathrm{P}=0.036$, respectively).

\section{Number of Medications}

We found that an increase in the number of drugs also increases the likelihood of having DRP by 1.20 times (95\% CI, 0.78 to $1.72, \mathrm{P}=0.00005$ ).

\section{Age, Weight, and Gender}

There was no significant difference in DRP incidence between DRP and age (mean 3.5, $\mathrm{P}=0.389$ ), gender mean $(\mathrm{P}=0.436)$, and weight (mean 13.47, $\mathrm{P}=0.323$ ).

Tables 5 and 6 summarize risk factor analysis associated with preventable DRPs.

\section{Discussion}

The findings of our study showed that a significant number of preventable DRPs were identified among the hospitalized children. The number of patients who experienced at least one DRP was 235, among whom 319 DRPs were recorded. The overall incidence of DRPs was 48.7\% (319/655). The rate of preventability from all detected DRPs was $87.8 \%$ (280/319), which represents a safety concern. The high incidence of preventable DRP in our results was comparable to the incidence reported in a Hong Kong study (51.2\%). ${ }^{35}$

The medical ward was found to have the highest recorded number of preventable DRPs (92/280, 32.9\%) compared to other pediatric wards. Overall, the most reported cause and type of preventable DRPs across pediatric wards was dosing problems at $65.5 \%(209 / 319)$, which is consistent with the findings of previously published studies that addressed DRPs among pediatric patients at ward level and at emergency

Table 4 Frequency of Identified Preventable DRPs' Category per Study Area Classified According to PCNE Classification (V.7)

\begin{tabular}{|c|c|c|c|c|c|c|c|}
\hline $\begin{array}{l}\text { DRPs Category, Total } \\
(\%, n * / N)\end{array}$ & Classification & $\begin{array}{l}E D \\
n=48\end{array}$ & $\begin{array}{l}\text { Surgical } \\
n=77\end{array}$ & $\begin{array}{l}\text { Medical } \\
\mathrm{n}=92\end{array}$ & $\begin{array}{l}\text { PICU } \\
n=30\end{array}$ & $\begin{array}{l}\text { NICU } \\
n=33\end{array}$ & $\begin{array}{l}\text { DRP } \\
\text { Incidence } \\
\left(\%, n^{b} / N^{a}\right)\end{array}$ \\
\hline $\begin{array}{l}\text { I-Dosing problems } \\
(74.6 \%, n=209 / 280)\end{array}$ & $\begin{array}{l}\text { Dose too low } \\
\text { Dose too high }\end{array}$ & $\begin{array}{l}39 \\
3\end{array}$ & $\begin{array}{l}38 \\
16\end{array}$ & $\begin{array}{l}67 \\
14\end{array}$ & $\begin{array}{l}15 \\
5\end{array}$ & $\begin{array}{l}5 \\
7\end{array}$ & $\begin{array}{l}58.6 \%, 164 / 280 \\
16.1 \%, 45 / 280\end{array}$ \\
\hline $\begin{array}{l}\text { 2-Drug choice problems } \\
(22.9 \%, n=64 / 280)\end{array}$ & $\begin{array}{l}\text { Duplication of drug } \\
\text { No clear indication for the drug } \\
\text { Contraindications } \\
\text { Inappropriate drug } \\
\text { Drug interaction }\end{array}$ & $\begin{array}{l}0 \\
1 \\
0 \\
4 \\
0\end{array}$ & $\begin{array}{l}0 \\
7 \\
2 \\
11 \\
0\end{array}$ & $\begin{array}{l}1 \\
4 \\
0 \\
4 \\
0\end{array}$ & $\begin{array}{l}0 \\
1 \\
1 \\
5 \\
2\end{array}$ & $\begin{array}{l}0 \\
11 \\
3 \\
7 \\
0\end{array}$ & $\begin{array}{l}0.4 \%, 1 / 280 \\
8.6 \%, 24 / 280 \\
2.1 \%, 6 / 280 \\
11.1 \%, 31 / 280 \\
0.7 \%, 2 / 280\end{array}$ \\
\hline $\begin{array}{l}\text { 3-Drug use problems } \\
(2.5 \%, n=7 / 280)\end{array}$ & $\begin{array}{l}\text { Treatment duration too long } \\
\text { Inappropriate drug monitoring } \\
\text { Drug omission }\end{array}$ & $\begin{array}{l}1 \\
0 \\
0\end{array}$ & $\begin{array}{l}1 \\
0 \\
2\end{array}$ & $\begin{array}{l}1 \\
0 \\
1\end{array}$ & $\begin{array}{l}0 \\
1 \\
0\end{array}$ & $\begin{array}{l}0 \\
0 \\
0\end{array}$ & $\begin{array}{l}I .1 \%, 3 / 280 \\
0.3 \%, 1 / 280 \\
I .1 \%, 3 / 280\end{array}$ \\
\hline
\end{tabular}

Notes: ${ }^{\mathrm{a}} \%$ calculated of total number of preventable DRPs identified in each ward; ${ }^{\mathrm{b}}$ Frequency of identified preventable DRPs, as one child can contribute to more than one preventable DRP.

Abbreviations: PCNE, Pharmaceutical Care Network Europe; DRPs, preventable drug-related problems; ED, emergency department; PICU, pediatric intensive care unit; NICU, neonatal intensive care unit; $n$, number of included patients with preventable DRPs per study area; $N$, total number of patients with preventable DRPs. 
Table 5 Risk Factors Associated with Preventable DRPs (Location, Type of Admission, and Number of Medications)

\begin{tabular}{|c|c|c|c|c|}
\hline \multicolumn{2}{|l|}{ Risk Factors } & \multirow{2}{*}{$\begin{array}{l}\text { OR } \\
1.27 \\
3.31 \\
2.97 \\
4.44 \\
1\end{array}$} & \multirow{2}{*}{$\begin{array}{l}95 \% \mathrm{Cl} \\
0.75-2.16 \\
1.95-5.62 \\
1.87-4.74 \\
1.87-10.52 \\
-\end{array}$} & \multirow{2}{*}{$\begin{array}{l}\text { P-Value } \\
0.337 \\
0.0000 \text { I* } \\
0.0000 \text { I* } \\
0.0000 \text { I* } \\
\text { - }\end{array}$} \\
\hline Location & $\begin{array}{l}\text { ED } \\
\text { Surgical } \\
\text { Medical } \\
\text { PICU } \\
\text { NICU }\end{array}$ & & & \\
\hline Type of admission & $\begin{array}{l}\text { Transferred } \\
\text { ED } \\
\text { Scheduled }\end{array}$ & $\begin{array}{l}1 \\
1.8 \\
2.89\end{array}$ & $\begin{array}{l}- \\
\text { I.45-4.42 } \\
\text { I.83-4.70 }\end{array}$ & $\begin{array}{l}- \\
0.036^{*} \\
0.005^{*}\end{array}$ \\
\hline \multicolumn{2}{|c|}{ Number of medications } & 1.2 & $0.78-1.72$ & $0.00005^{*}$ \\
\hline
\end{tabular}

Notes: Binary logistic regression used to summarize the association between DRP and location, type of admission, and number of medications. *Significant at 0.05 . Abbreviations: DRPs, preventable drug-related problems; ED, emergency department; PICU, pediatric intensive care unit; NICU, neonatal intensive care unit; $O R$, odds ratio; $95 \% \mathrm{Cl}, 95 \%$ confidence interval.

Table 6 Variables Associated with Preventable DRPs (Location, Type of Admission, and Number of Medications)

\begin{tabular}{|c|c|c|}
\hline \multicolumn{3}{|c|}{$\begin{array}{l}\text { (A) Chi-square test to summarize the association between } \\
\text { DRP and location, type of admission, and gender }\end{array}$} \\
\hline Variable & Chi-square & P-Value \\
\hline Location & 33.508 & $0.00001 *$ \\
\hline Type of admission & 14.186 & $0.001 *$ \\
\hline Gender & 0.608 & 0.436 \\
\hline
\end{tabular}

(B) T-test for independent variables to summarize the association between DRP and age, weight, and number of medications

\begin{tabular}{|l|l|l|}
\hline Variable & T statistic & P-Value \\
\hline Age & 0.862 & 0.389 \\
Weight & 0.989 & 0.323 \\
Number of medications & 8.755 & $0.00005^{*}$ \\
\hline
\end{tabular}

Notes: Binary logistic regression used to summarize the association between DRP and age, weight, and number of medications. *Significant at 0.05 .

departments. ${ }^{23-34}$ A couple of study results have shown that the majority of DRPs were associated with inappropriate drug selection, drug dosing, and dosing interval. ${ }^{27,28,34} \mathrm{As}$ we have described, dosing problems were the most reported cause of preventable DRPs in every pediatric ward. The medical ward had $28.9 \%$ preventable DRPs (67 dose too low and 14 dose too high, 81/280), surgical ward had $19.3 \%$ (38 dose too low and 16 dose too high, 54/280), emergency department had 15\% (39 dose too low and 3 dose too high, 42/280), PICU had 7.1\% (15 dose too low and 5 dose too high, 20/280), and NICU 4.3\% (5 dose too low and 7 dose too high, 12/280). A standardized drug dosing guide was used as strategy to eliminate drug-dosing errors among children visiting the emergency department unit. ${ }^{36}$

The current study results showed a high number of DRP occurrences related to drug dosing problems in pediatric which could be attributed to several factors. Increasing the number of prescribed medications, patients admitted for a longer time or admitted post-emergency department visits were the ones more likely to receive inappropriate doses and use different drug dosing references. Additional factors we observed but were not adequately assessed in our study include staff unfamiliarity with drug dosing among the pediatric population (newly hired staff, new residents or fellows), different working shifts (off-hours working duty, night, evening, weekend staffing, different rotating residents and fellows) - these were found to be associated with DRPs. We believed that the lack of specific impeded CCDS pediatric dosing in the CPOE system at KAMC-J is a major contributing factor to the high incidence of drug-dosing errors associated with preventable DRPs. Well-trained pharmacists and the active participation of a patient-rounding team will play a major role in reducing the incidence of adverse drug events (ADEs) by two-thirds. ${ }^{38}$ However, age and gender were found not to be significantly associated with DRPs, which corresponds to the results in our previous studies. ${ }^{29,30}$

To avoid discrepancy in methodology, we conducted this study using standardized international terminologies were used: the Anatomic Therapeutic Chemical (ATC) classification (WHO-ATC) for medication group, and the International Classification of Diseases version 10 (WHO-ICD 10) for diagnoses, and we used standardized methods for data collection, validated by the updated PCNE classification system for DRPs, while the chart review which was used as the main methodology in our previous studies has been well tested in the United States and European countries. ${ }^{29-31,35,37}$ On the other hand, when interpreting the study results, a couple of limitations can be considered. This study's findings represent a single institution experience. Although we recently reported the impact of the CPOE system in the reduction of DRP incidences among hospitalized children, the current study results showed that preventable DRPs at KAMC-J are quite common $(87.7 \%)$. We did not asses the outcome of preventable DRPs or the use of medicine in off-label pattern outside the indication in pediatric - all of which should be considered in future studies.

\section{Conclusion}

The findings of this study showed a high incidence of preventable DRPs which was related to dosing and drug 
choice problems. The results of this observational study may be used to establish the most appropriate prevention strategies for designing a specific, imbedded pediatric CCDS in the CPOE system, using a unified pediatric dosing guide protocol toward safe medicine use among this vulnerable patient population.

\section{Acknowledgment}

The authors wish to thank Mr. Mohamed Eldigre Ahmed for his vital and selfless help with the statistical analysis.

This manuscript has been presented as a poster abstract in the following conferences:

1. Patient Safety Forum 2019, Jeddah, Saudi Arabia, and abstract was published in the conference proceedings of BMJ journal, page 87, available at https://patient safety.ksau-hs.edu.sa/Documents/2019\%20Conference \%20Proceedings.pdf.

2. 28th Annual PPAG Meeting and 2019 Pediatric Pharmacy Conference

\section{Author Contributions}

All authors contributed to data analysis, drafting or revising the article, gave final approval of the version to be published, and agree to be accountable for all aspects of the work.

\section{Funding}

This project did not receive any specific grant from funding agencies in the public, commercial, or not-for-profit sectors.

\section{Disclosure}

The authors report no conflicts of interest in this work.

\section{References}

1. Nebeker JR, Barach P, Samore MH. Clarifying adverse drug events: a clinician's guide to terminology, documentation, and reporting. Ann Intern Med. 2004;140:795-801. doi:10.7326/0003-4819-140-10200405180-00009

2. Edwards IR, Aronson JK. Adverse drug reactions: definitions, diagnosis, and management. Lancet. 2000;356:1255-1259. doi:10.1016/ S0140-6736(00)02799-9

3. Schatz SN, Weber RJ Adverse drug reactions. ACCP (American College of Clinical Pharmacy). CNS/Pharmacy Practice, PSAP; 2015. Available from: https://www.accp.com/docs/bookstore/psap/ 2015B2.SampleChapter.pdf., Accessed March 3, 2018.

4. Leape LL. Preventing adverse drug events. Am J Health Syst Pharm. 1995;52(4):379-382. doi:10.1093/ajhp/52.4.379

5. NCCMERP. National coordinating council for medication error reporting and prevention, about medication errors: what is a medication error? Available from: http://www.nccmerp.org/aboutMedErrors.html. Accessed March 03, 2018.
6. Pharmaceutical Care Network Europe (PCNE). 2017. Available from: http://www.pcne.org/working-groups/2/drug-related-problemclassification. Accessed April 26, 2018.

7. Strand LM, Morley PC, Cipolle RJ, Ramsey R, Lamsam GD. Drug-related problems: their structure and function. DICP. 1990;24:1093-1097. doi: $10.1177 / 106002809002401114$

8. Westerlund T, Marklund B. Assessment of the clinical and economic outcomes of pharmacy interventions in drug-related problems. J Clin Pharm Ther. 2009;34:319-327. doi:10.1111/jcp.2009.34.issue-3

9. Easton KL, Chapman CB, Brien J-AE. Frequency and characteristics of hospital admissions associated with drug-related problems in paediatrics. Br J Clin Pharmacol. 2004;57:611-615. doi:10.1111/ bcp.2004.57.issue-5

10. Angamo MT, Curtain CM, Chalmers L, et al. Predictors of adverse drug reaction-related hospitalisation in Southwest Ethiopia: a prospective cross-sectional study. PLoS One. 2017;12:e186631. doi:10.1371/journal.pone.0186631

11. Kalisch LM, Caughey GE, Barratt JD, et al. Prevalence of preventable medication-related hospitalizations in Australia: an opportunity to reduce harm. Int J Qual Health Care. 2012;24:239-249. doi:10.1093/intqhe/mzs015

12. Runciman WB, et al. Adverse drug events and medication errors in Australia. Int J Qual Health Care. 2003;15:i49-i59. doi:10.1093/ intqhe/mzg085

13. Singh H, Kumar BN, Sinha T, Dulhani N. The incidence and nature of drug-related hospital admission: a 6-month observational study in a tertiary health care hospital. J Pharmacol Pharmacother. 2011;2:17-20. doi:10.4103/0976-500X.77095

14. Pedrós C, Quintana B, Rebolledo M, et al. Prevalence, risk factors and main features of adverse drug reactions leading to hospital admission. Eur J Clin Pharmacol. 2014;70:361-367. doi:10.1007/ s00228-013-1630-5

15. Urbina $\mathrm{O}$, Ferrández $\mathrm{O}$, Grau $\mathrm{S}$, et al. Design of a score to identify hospitalized patients at risk of drug-related problems. Pharmacoepidemiol Drug Saf. 2014;23:923-932. doi:10.1002/ pds.v23.9

16. Taketomo CK, Hodding JH, Kraus DM. Pediatric Dosage Handbook: Including Neonatal Dosing, Drug Administration, \& Extemporaneous Preparations. 17th ed. Hudson, Ohio: Lexi-Comp Inc; 2010.

17. BNF for Children. British National Formulary for Children. London: British Medical Association, the Royal Pharmaceutical Society of Great Britain, the Royal College of Paediatrics and Child Health, and the Neonatal and Paediatric Pharmacists Group; 2009.

18. Arcara KM, Tschudy MM. The Harriet Lane Handbook: A Manual for Pediatric House Officers. 19th ed ed. Philadelphia, PA: Mosby Elsevier; 2012.

19. Wong IC, Wong LY, Cranswick NE. Minimising medication errors in children. Arch Dis Child. 2009;94(2):161-164. doi:10.1136/adc.2007. 116442

20. Standing JF, Tuleu C. Paediatric formulations-getting to the heart of the problem. Int J Pharm. 2005;300(1-2):56-66. doi:10.1016/j. ijpharm.2005.05.006

21. Dormann H, Muth-Selbach U, Krebs S, et al. Incidence and costs of adverse drug reactions during hospitalisation: computerised monitoring versus stimulated spontaneous reporting. Drug Saf. 2000;22 (2):161-168. doi:10.2165/00002018-200022020-00007

22. Holdsworth MT, Fichtl RE, Behta M, et al. Incidence and impact of adverse drug events in pediatric inpatients. Arch Pediatr Adolesc Med. 2003;157(1):60-65. doi:10.1001/archpedi.157.1.60

23. Zargarzadeh AH, Emami MH, Hosseini F. Drug related hospital admissions in a generic pharmaceutical system. Clin Exp Pharmacol Physiol. 2007;34(5-6):494-498. doi:10.1111/cep.2007.34.issue-5-6

24. Radley DC, Wasserman MR, Olsho LE, et al. Reduction in medication errors in hospital due to adaption of computerized provider order entry systems. J Am Med Inform Assoc. 2013;20(3):470-476. doi:10.1136/amiajnl-2012-001241 
25. Mekhjian HS, Kumar RR, Kuehn L, et al. Immediate benefits realized following implementation of physician order entry at an academic medical center. J Am Med Inform Assoc. 2002;9(5):529-539. doi:10.1197/jamia.M1038

26. Ammenwerth E, Schnell-Inderst P, Machan C, Siebert U. The effect of electronic prescribing on medication errors and adverse drug events: a systemic review. $J$ Am Med Inform Assoc. 2008;15 (5):585-600. doi:10.1197/jamia.M2667

27. Fortescue EB, Kaushal R, Landrigan CP, et al. Prioritizing strategies for preventing medication errors and adverse drug events in pediatric inpatients. Pediatrics. 2003;111(4 Pt 1):722-729. doi:10.1542/ peds.111.4.722

28. Bates DW, Leape LL, Cullen DJ, et al. Effect of computerized physician order entry and a team intervention on prevention of serious medication errors. JAMA. 1998;280(15):1311-1316. doi:10.1001/jama.280.15.1311

29. Rashed AN, Neubert A, Tomlin S, et al. Epidemiology and potential associated risk factors of drug-related problems in hospitalised children in the United Kingdom and Saudi Arabia. Eur J Clin Pharmacol. 2012;68(12):1657-1666. doi:10.1007/s00228-012-1302-x

30. Rashed AN, Neubert A, Alhamdan H, et al. Drug-related problems found in children attending an emergency department in Saudi Arabia and in the United Kingdom. Int J Clin Pharm. 2013;35(3):327-331. doi:10.1007/s11096-013-9758-z

31. AlAzmi A, AlHamdan H, Ahmed O, et al. Impact of the e-prescribing system on the incidence and nature of drug-related problems in children in a Saudi hospital. Int J Pharm Pract. 2019. doi:10.1111/ ijpp. 12548

32. El Morabet N, Uitvlugt EB, van den Bemt BJF, et al. Prevalence and preventability of drug-related hospital readmissions: a systematic review. J Am Geriatr Soc. 2018;66(3):602-608. doi:10.1111/jgs.15244

33. Morimoto T, Gandhi TK, Seger AC, et al. Adverse drug events and medication errors: detection and classification methods. Qual Saf Health Care. 2004;13(4):306-314. doi:10.1136/qshc.2004.010611

34. Kaushal R, Bates DW, Landrigan C, et al. Medication errors and adverse drug events in pediatric inpatients. JAMA. 2001;285:2114-2120. doi:10.1001/jama.285.16.2114

35. Rashed AN, Wilton L, Lo CC, et al. Epidemiology and potential risk factors of drug-related problems in Hong Kong paediatric wards. $\mathrm{Br}$ J Clin Pharmacol. 2014;77(5):873-879. doi:10.1111/bcp.12270
36. Aseeri MA. The impact of a pediatric antibiotic standard dosing table on dosing errors. J Pediatr Pharmacol Ther. 2013;18(3):220-226. doi:10.5863/1551-6776-18.3.220

37. Rashed AN, Wong IC, Cranswick N, et al. Adverse drug reactions in children - international surveillance and evaluation (ADVISE): a multicentre cohort study. Drug Saf. 2012;35:481-494. doi:10.2165/ 11597920-000000000-00000

38. Moyen E, Camire E, Stelfox HT. Clinical review: medication errors in critical care. Crit Care. 2008;12(2):208. doi:10.1186/cc6813

39. ICH Guideline: International Conference on Harmonisation (ICH) Guideline. E11: Clinical Investigation of Medicinal Products in the Paediatric Population. London, UK: European Medicines Agency for the Evaluation of Medicinal Products (EMEA); 2001. Available from: http://www.ema.europa.eu/docs/en_GB/document_library/Scientific guideline/2017/10/WC500236218.pdf. Accessed August 26, 2019.

40. Ahmed MEBK. Drug-associated admissions to a district hospital in Saudi Arabia. J Clin Pharm Ther. 1997;22(1):61-66. doi:10.1046/ j.1365-2710.1997.8375083.x

41. Al-Olah YH, Al-Thiab KM. Admissions through the emergency department due to drug-related problems. Ann Saudi Med. 2008;28 (6):426-429. doi:10.5144/0256-4947.2008.426

42. Ghaleb MA, Barber N, Franklin BD, Wong ICK. The incidence and nature of prescribing and medication administration errors in paediatric inpatients. Arch Dis Child. 2010;95:113-118. doi:10.1136/ adc. 2009.158485

43. Dean B, Schachter M, Vincent C, Barber N. Prescribing errors in hospital inpatients: their incidence and clinical significance. Qual Saf Health Care. 2002;11:340-344. doi:10.1136/qhc.11.4.340

44. Schumock GT, Thornton JP. Focusing on the preventability of adverse drug reactions. Hosp Pharm. 1992;27:538.

45. Dean BS, Barber ND. A validated, reliable method of scoring the severity of medication errors. Am J Health Syst Pharm. 1999;56:57-62. doi:10.1093/ajhp/56.1.57

46. International Classification of Diseases Version 10. Available from: http:// www.who.int/classifications/icd/en/. Accessed November 22, 2019.

47. WHO Anatomic Therapeutic Chemical Classification. Available from: http://www.whocc.no/atc_ddd_index/. Accessed August 25, 2019.
Drug, Healthcare and Patient Safety

\section{Publish your work in this journal}

Drug, Healthcare and Patient Safety is an international, peer-reviewed open-access journal exploring patient safety issues in the healthcare continuum from diagnostic and screening interventions through to treatment, drug therapy and surgery. The journal is characterized by the rapid reporting of reviews, original research, clinical, epidemiological and post-marketing surveillance studies, risk management, health literacy and educational programs across all areas of healthcare delivery. The manuscript management system is completely online and includes a very quick and fair peer-review system. Visit http://www.dovepress.com/testimonials.php to read real quotes from published authors. 